\title{
Uncontrolled hypertension and associated factors among adult hypertensive patients on follow-up at Jimma University Teaching and Specialized Hospital: cross-sectional study
}

This article was published in the following Dove Press journal:

Research Reports in Clinical Cardiology

30 March 2017

Number of times this article has been viewed

\author{
Bekele Tesfaye' \\ Dessalegn Haile' \\ Benalfew Lake' \\ Tefera Belachew ${ }^{2}$ \\ Temamen Tesfaye ${ }^{3}$ \\ Habtamu Abera ${ }^{4}$ \\ 'Department of Nursing, College \\ of Health Science, Debre Markos \\ University, Debre Markos, \\ ${ }^{2}$ Department of Population and Family \\ Health, ${ }^{3}$ Department of Nursing and \\ Midwifery, College of Health Science, \\ Jimma University, Jimma, ${ }^{4}$ Department \\ of Nursing and Midwifery, College \\ of Health Sciences, School of \\ Allied Health Sciences, Addis Ababa \\ University, Addis Ababa, Ethiopia
}

Introduction: Hypertension, including poorly controlled blood pressure, is the major global health problem that affects one billion people worldwide. Limited studies have been conducted on prevalence of uncontrolled hypertension and associated factors among adult hypertensive patients in Ethiopia.

Objective: The aim of this study was to determine the prevalence of uncontrolled hypertension and associated factors among adult hypertensive patients at Jimma University Teaching and Specialized Hospital.

Methods: Institution-based cross-sectional study was conducted at the chronic illness clinic of Jimma University Specialized and Teaching hospital from March 09 to April 13, 2016. A total of 345 hypertensive patients were selected using systematic sampling technique. Data were collected using structured questionnaire through face-to-face exit interview and chart review. Data were analyzed using Statistical Package for the Social Sciences (SPSS) version 20.0 software. The bivariate and multivariable analysis was done to identify factors of uncontrolled hypertension. Results: More than half, $52.7 \%$, of the patients had uncontrolled hypertension. Lack of awareness of hypertension-related complications (adjusted odds ratio $[\mathrm{AOR}]=2.140,95 \%$ confidence interval $[\mathrm{CI}]=1.272-3.600, p=0.004)$, nonadherent to smoking abstinence $(\mathrm{AOR}=3.935$, 95\% CI $=1.065-14.535, p=0.004)$, nonadherent to alcohol abstinence (AOR=2.477, 95\% $\mathrm{CI}=1.074-5.711, p=033)$, Khat (Catha edulis) chewing $(\mathrm{AOR}=2.518,95 \% \mathrm{CI}=1.250-5.073$, $p=0.010)$, overweight $(\mathrm{AOR}=2.241,95 \% \mathrm{CI}=1.239-4.053, p=0.008)$, middle age ( $\mathrm{AOR}=7.893$, $95 \% \mathrm{CI}=1.860-33.493, p=0.008)$, and old age $(\mathrm{AOR}=9.944,95 \% \mathrm{CI}=2.523-39.188, p=0.001$ were significant predictors of uncontrolled hypertension.

Conclusion: The prevalence of uncontrolled hypertension was high at Jimma University Teaching and Specialized hospital among patients with hypertension. Unhealthy lifestyles were major factors. Continuous health education on lifestyle practices and hypertension-related complications in each follow-up visit through nurses, physicians, and pharmacists are very essential to avert the problem.

Keywords: unhealthy life style, uncontrolled, hypertension, risk factors

\section{Background}

Hypertension is defined as a persistent systolic blood pressure (BP) reading (SBP) of $140 \mathrm{~mm} \mathrm{Hg}$ or greater and/or a diastolic blood pressure reading (DBP) of $90 \mathrm{~mm} \mathrm{Hg}$ or greater. ${ }^{1}$ It is known as uncontrolled if SBP is $\geq 140 \mathrm{~mm} \mathrm{Hg}$ and/or DBP $\geq 90 \mathrm{~mm} \mathrm{Hg}$ for general hypertensive population, or SBP $\geq 130 \mathrm{~mm} \mathrm{Hg}$ and/or DBP $\geq 80 \mathrm{~mm} \mathrm{Hg}$ in patients with established diabetes mellitus (DM) or chronic kidney disease (CKD).
Correspondence: Bekele Tesfaye Department of Nursing, College of Health Science, Debre Markos University, Debre Markos 269, Ethiopia Email bekeletesfaye76@gmail.com 
This classification is based on average of two or more measurement on two or more office visits. ${ }^{2}$

Consultative review report for the 6th Session of the African Union Ministers of Health conference on noncommunicable diseases indicated that hypertension has been regarded as a disease of high-income society but this has changed radically in the previous decades with hypertension now higher in Africa than western countries. ${ }^{3}$ Similarly, in sub-Saharan Africa (SSA) including Ethiopia, adult hypertensive population is predicted to be 150 million by $2025 .^{4}$

Uncontrolled hypertension is common among patients taking treatment and is a major public health problem in both developed and developing countries. A study conducted in the USA in older adults (65 years and above) revealed that presence of uncontrolled hypertension was highly prevalent and estimated as $54 \% .^{5}$

Nearly one-third of US adults had hypertension; about half (36 million) had uncontrolled hypertension. ${ }^{6}$ Hypertension and its poor control are the most often observed risk factors for cardiovascular disease (CVD) in both urban and rural communities in SSA with controlled hypertension ranging from $2.6 \%$ in Kenya to $17.8 \%$ in Namibia as systemic review indicated. ${ }^{7}$ Few studies conducted in Ethiopia justified that the prevalence of uncontrolled hypertension among patients on treatment varied from $53.4 \%$ in Gondar hospital to $59.9 \%$ in Tikur Anbessa Hospital. ${ }^{8,9}$

Cardiovascular-related morbidity and mortality is the most adverse outcome of poorly controlled hypertension, ${ }^{10}$ which is also responsible for occurrence of stroke (accounting for $51 \%$ of all stroke deaths worldwide), ischemic heart disease ( $45 \%$ of all deaths), CKD, congestive heart failure, aortic aneurysm, and peripheral arterial disease. ${ }^{11}$ It also leads to ventricular remodeling, complex ventricular arrhythmias, repolarization abnormalities, and autonomic dysfunction. ${ }^{12}$

Evidences had shown that the problem of uncontrolled hypertension revolves mainly around nonadherence to medication, lifestyle modifications and obesity, presence of comorbidity including DM, CKD, and advanced age. ${ }^{13-16}$ Moreover, financial and geographical accessibility of the available health institutions, the accessibility, and clinical practice of clinicians such as nurses and physicians together with the presence of essential medicines have been reported as essential factors in the control of high BP among health service-related factors. ${ }^{15,16}$

Although attention has been given on processing strategies that improve adherence to treatment regimens like self-care behaviors for better BP control, ${ }^{17-19}$ majority of the patients in health care facility received medication but not lifestyle education, indicating partial adherence to JNC7 guidelines. For instance, on average, only $30 \%$ of hypertension patients practice lifestyle modifications as a treatment of hypertension. ${ }^{20}$ Thus, the problem is worst in least-developed countries like Ethiopia, which points to a low level of screening and follow-up. In addition, the burden of uncontrolled hypertension has negative impact on the limited health care budget of the country at national level. Although a few attempts to determine the prevalence of hypertension have been established in Ethiopia, there is limited data on control rates of it among patients on treatment. Thus, control of hypertension among hypertensive patients has tremendous public health benefits. Therefore, this study was intended to determine the prevalence of uncontrolled hypertension in relation to various contributing factors among patients on follow-up at Jimma University Specialized and Teaching Hospital.

\section{Methods}

\section{Study design and Setting}

Cross-sectional study design was conducted at Jimma University Specialized and Teaching Hospital from March 09 to April 13, 2016. It is located in Jimma city $352 \mathrm{~km}$ southwest of Addis Ababa. It is a teaching and referral hospital, providing services for $\sim 15,000$ inpatients, 160,000 outpatient attendants, 11,000 emergency cases, and 4500 deliveries in a year coming to the hospital from the catchment population of about 15 million people.

Chronic illness care is one of the services the hospital provides at its chronic illness clinic to the population both within and outside of Jimma town. There were 1700 patients taking antihypertensive treatment at the chronic illness follow-up care unit according to data registered in 2016 prior to data collection period.

\section{Sample size and sampling technique}

The sample size was calculated using a formula for estimation of a single population. A total of 1700 hypertensive patients constituted the source population. The assumptions considered during calculation of the sample size were $53.4 \%$ prevalence of uncontrolled hypertension from a study conducted at Gondar university hospital ${ }^{8}$ and $95 \%$ confidence level and margin of error of 5\%. By applying the correction formula and adding $10 \%$ nonresponse rate, the final sample size became 345 hypertensive patients. Systematic sampling was used to select 330 study participants ( $\geq 18$ years) with hypertension who were on treatment for at least 6 months. The first case was selected by lottery method within the sampling interval. Then using the interval the rest of the cases were selected. 
Registration numbers of the patients who were on follow-up and eligible were taken. Patients younger than 18 years, who were too ill to be interviewed, those with missing BP measurements in two previous visits, and pregnant women because of the effect of physiology of pregnancy on BP were excluded.

\section{Data collection}

The research instrument was developed after revising similar articles on uncontrolled hypertension and associated factors. ${ }^{21,22,23,24}$ It contains sociodemographic and economic factors, ${ }^{21}$ knowledge on self-care ${ }^{22}$ and complications of hypertension, ${ }^{23}$ clinical conditions, anthropometric conditions, ${ }^{24}$ and Hypertension Self-Care Activity Level Effects (H-SCALE). ${ }^{25}$ The patient chart was reviewed and physical measurements were conducted. Adherence to self-care activities and medication were measured using the H-SCALE, adopted from the literature and contextualized to a local context. The internal consistency of the H-SCALE was assessed using Cronbach's alpha. All self-care domains had acceptable to good and very good Cronbach $\alpha$ 's, indicating that the scale is consistent and reproducible for use. The specific values include medication $(\alpha=0.755)$, physical activity $(\alpha=0.891)$, low-salt $\operatorname{diet}(\alpha=0.73)$, weight management $(\alpha=0.835)$, and alcohol use $(\alpha=0.918)$. Face and content validity of the final version of the questionnaire was judged by three postgraduate pharmacy holder individuals, two BSc nurses, and two internists before and after pretest.

Client's chart was reviewed to retrieve medical information (drug information, comorbid cases, and the representative $\mathrm{BP}$, which was the $\mathrm{BP}$ reading from the most recent visit [last three consecutive appointments including data collection day]). Physical measurements such as height and weight were measured, and then body mass index (BMI) was calculated.

Six diploma nurses and two BSc nurses were recruited to conduct the data collection and supervision, respectively, based on their previous experience on data collection and ability to speak both Amharic and Afaan Oromo. Training and practical demonstrations on interview techniques and measurement procedure were given to data collectors one day before data collection. Supervision of data collection was done by supervisors.

\section{Data analysis}

Data were coded and entered into Epi data version 3.1 and exported to Statistical Package for the Social Sciences (SPSS) version 20 (IBM Corporation, Armonk, NY, USA) for statistical analysis.

Descriptive statistics (frequencies, percentages, mean values, and standard deviations [SDs]) were calculated for demographic and health characteristics and to assess participants' BP control status. Results were reported as percentages (frequency) for categorical variables or means with SDs for continuous variables (age, years of treatment, SBP, and DBP), $p$-values ( $p<0.25$ ), and crude odds ratios, and $95 \%$ confidence intervals (CIs) were used to present results of the bivariate analysis.

All predictor variables that had a significant association in bivariate analysis with $p$-value $<0.25$ were entered into multivariable logistic regression model to assess the association between dependent and independent variables.

Multivariable logistic regression model with backward likelihood ratio method was performed to evaluate predictors of uncontrolled hypertension. Statistical significance was defined at a probability level of 0.05 . Hosmer-Lemeshow goodness-of-fit statistic was used to check model fitness, and the model had a $p=0.239$ ( $>0.05)$.

Ethical approval was obtained from the Ethical Review Committee of Jimma University. Participants provided written informed consent before the interviews. Privacy, anonymity, and confidentiality were ensured throughout the process of the study. The study participants also were informed that refusal to consent or withdrawal from the study does not alter or put at risk their access to care.

\section{Results}

Out of 345 hypertensive patients planned to be included in the study, 330 were interviewed, eight refused to participate because of lack of time to complete the interview, and seven were too sick to be interviewed, which gives a response rate of $95.6 \%$.

\section{Sociodemographic characteristics of the respondents}

The mean age $( \pm \mathrm{SD})$ of the participants was $56.4( \pm 13.9)$ years and around half $(52.7 \%)$ were females. Two hundred sixteen $(65.5 \%)$ of the participants were married. About a quarter $(24.8 \%)$ were housewives, $58.8 \%$ of the participants were Oromos, and $47.0 \%$ were Muslim followers. Out of all participants $42.1 \%$ had no formal education. The majority of the respondents, $57.9 \%$, were urban dwellers (Table 1 ).

\section{Prevalence of uncontrolled hypertension and subtypes}

The three consecutive follow-up average SBP of the patients was $128.44 \pm 17.73 \mathrm{~mm} \mathrm{Hg}$. The mean DBP of the patients was $78.02 \pm 17.062 \mathrm{~mm} \mathrm{Hg}$. The three consecutive follow-up average $\mathrm{BP}$ of the patients revealed that the overall prevalence of uncontrolled hypertension was 174 (52.7\%) with 95\% $\mathrm{CI}=47.3 \%-58.1 \%$. 
Table I Sociodemographic characteristics of hypertensive patients who were attending at Jimma University Specialized and Teaching, Jimma, southwest Ethiopia, 2016

\begin{tabular}{|c|c|c|}
\hline Variables & Category & Frequency (\%) \\
\hline \multirow[t]{2}{*}{ Sex } & Male & $156(47.3)$ \\
\hline & Female & $174(52.7)$ \\
\hline \multirow[t]{4}{*}{ Marital status } & Single & $10(3.0)$ \\
\hline & Married & $216(65.5)$ \\
\hline & Divorced & $38(11.5)$ \\
\hline & Widowed & $66(20.0)$ \\
\hline \multirow[t]{5}{*}{ Religion } & Orthodox & $126(38.2)$ \\
\hline & Protestant & $42(12.7)$ \\
\hline & Muslim & $155(47.0)$ \\
\hline & Catholic & $3(0.9)$ \\
\hline & Wakafeta & $4(1.2)$ \\
\hline \multirow[t]{4}{*}{ Educational level } & No formal education & $139(42.1)$ \\
\hline & Primary education ( $1-8$ grade) & $100(30.3)$ \\
\hline & Secondary education (9-12 grade) & $41(12.4)$ \\
\hline & College and above & $50(15.2)$ \\
\hline \multirow[t]{6}{*}{ Occupation } & Government employee & $74(22.4)$ \\
\hline & NGO employee & $52(15.8)$ \\
\hline & Merchant & $38(11.5)$ \\
\hline & Farmer & $74(22.4)$ \\
\hline & Housewife & $82(24.8)$ \\
\hline & Daily laborers & $10(3.0)$ \\
\hline \multirow[t]{5}{*}{ Ethnicity } & Oromo & $194(58.8)$ \\
\hline & Amhara & $5 I(I 5.5)$ \\
\hline & Kaffa & $35(10.6)$ \\
\hline & Dawro & $36(10.9)$ \\
\hline & Yem and Silitie & $14(4.2)$ \\
\hline \multirow[t]{2}{*}{ Residence } & Urban & 191 (57.9) \\
\hline & Rural & $139(42.1)$ \\
\hline \multirow[t]{3}{*}{ Family income } & $\leq 500$ & $88(26.7)$ \\
\hline & $501-2000$ & $188(57.0)$ \\
\hline & $>2000$ & $54(16.4)$ \\
\hline
\end{tabular}

Abbreviation: NGO, non governmental organization.

The prevalence of isolated diastolic hypertension, isolated systolic hypertension, and systolic diastolic hypertension was $22.7 \%, 18.8 \%$, and $11.2 \%$, respectively.

\section{Factors associated with} uncontrolled hypertension Knowledge about self-care behaviors and complications of hypertension

\section{of the study participants}

Regarding participant's knowledge about self-care activities, 219 (66.4\%) were knowledgeable and nearly half, 171 (51.8\%), had no knowledge on susceptibility to hypertensionrelated complications (Table 2).

\section{Adherence with lifestyle behaviors}

More than half of the participants, 196 (59.4\%), were reported as adherent to hypertension medication protocols.
Table 2 Knowledge status on self-care behaviors and awareness of hypertension-related complication among adult hypertensive patients, at Jimma University Specialized and Teaching, southwest Ethiopia, 2016

\begin{tabular}{llll}
\hline Variable category & Category & $\begin{array}{l}\text { Uncontrolled, } \\
\text { n (\%) }\end{array}$ & $\begin{array}{l}\text { Controlled, } \\
\text { n (\%) }\end{array}$ \\
\hline $\begin{array}{l}\text { Knowledge status on } \\
\text { self-care activities }\end{array}$ & Knowledgeable & I04 (47.5) & $70(63.1)$ \\
& $\begin{array}{l}\text { Not } \\
\text { knowledgeable }\end{array}$ & II5 (52.5) & $41(36.9)$ \\
$\begin{array}{l}\text { Awareness of } \\
\text { hypertension-related } \\
\text { complication }\end{array}$ & $\begin{array}{l}\text { Had awareness } \\
\text { Had no }\end{array}$ & II4 (42.0) & $83(58.0)$ \\
\hline
\end{tabular}

Table 3 Participants' adherence status on self-care behaviors (prevalence rates on self-care activity) among adult hypertensive patients, at Jimma University Specialized and Teaching, southwest Ethiopia, 2016

\begin{tabular}{lll}
\hline Variables & Category & Frequency (\%) \\
\hline Medication adherence & Adherence & $196(59.4)$ \\
& Nonadherence & $134(40.6)$ \\
Low-salt diet adherence & Adherence & $106(32.1)$ \\
& Nonadherence & $224(67.9)$ \\
Physical activity adherence & Adherence & $174(52.7)$ \\
& Nonadherence & $156(47.3)$ \\
Nonsmoking adherence & Adherence & $313(94.8)$ \\
Weight management adherence & Nonadherence & $17(5.2)$ \\
& Adherence & $112(33.9)$ \\
Alcohol abstinence adherence & Nonadherence & $218(66.1)$ \\
& Adherence & $285(86.4)$ \\
Khat (Catha edulis) abstinence & Nonadherence & $45(13.6)$ \\
& Adherence & $275(78.2)$ \\
Blood pressure check & Nonadherence & $55(21.8)$ \\
& $<2$ & $96(29.1)$ \\
& $\geq 2$ & $234(70.9)$ \\
\hline
\end{tabular}

More than two-third, 224 (67.9\%), were not following a low-salt diet and nearly half, 156 (43.3\%), were not engaging in physical activity on the last 1 week. Majority, 313 (94.8\%), of the participants were nonsmokers. Around two-third, 218 (66.1\%), of the participants were not adhered to weight management practices and more than three-fourth, 285(86.4\%), reported that they did not drink alcohol. Regarding Khat chewing, 275 (78.2\%) reported that they were not chewers. The majority of the patients, $234(70.9 \%)$, have got their BP measured two or more times in a month (Table 3).

\section{Biological characteristics (overweight, obesity) and number of regimen}

BMI was calculated after conducting physical measurements such as weight and height. Majority of participants, 214 (64.8\%), had normal body mass index, and regarding 
Table 4 Description of participants by body mass index, and number of antihypertensive drugs taken among adult hypertensive patients, at Jimma University Specialized and Teaching, southwest Ethiopia, 2016

\begin{tabular}{lll}
\hline Variables & Category & Frequency (\%) \\
\hline Body mass index & Normal weight & $214(64.8)$ \\
& Overweight & $96(29.1)$ \\
& Obesity & $20(6.1)$ \\
Number of antihypertensive drugs & I drug only & $30(9.1)$ \\
& 2 drugs & $154(46.7)$ \\
& $\geq 3$ drugs & $146(44.2)$ \\
\hline
\end{tabular}

medications, $154(46.7 \%)$ were on dual antihypertensive therapy (Table 4).

\section{Presence of comorbidity}

Comorbidity was checked after clinical data review from the patient card, and evidences of comorbidity, like DM, heart failure, or chronic renal disease, were not noted among the $228(69.1 \%)$ of the study participants.

\section{The bivariate and multivariable analysis}

Numerous associations were found to be significant in the bivariate analysis at $p$-value $<0.25$. Therefore, a multivariate approach was applied to determine which factors best explained and predicted uncontrolled hypertension as an outcome. Consequently, a number of independent variables such as lack of awareness of hypertension-related complication, nonadherence to smoking abstinence, nonadherence to alcohol abstinence, Khat (Catha edulis) chewing, overweight, and both middle and older age were significantly associated on multivariate analysis.

From the sociodemographic characteristics age was significantly associated, and patients found in the age range of 35-49 and $\geq 50$ are almost eight times and 10 times more likely to have uncontrolled hypertension compared to 18-34aged patients, respectively ([AOR $=7.893,95 \% \mathrm{CI}=1.860$ $33.493, p=0.005]$ and $[\mathrm{AOR}=9.944,95 \% \mathrm{CI}=2.523-39.188$, $p=0.001])$. On the other hand, overweight patients were two times more likely to have uncontrolled hypertension when compared to normal-weight patients $(\mathrm{AOR}=2.241,95 \%$ $\mathrm{CI}=1.239-4.053, p=0.008$ ).

Taking into consideration the respondents' awareness of hypertension-related complication, participants who did not know at least two complications were less likely to have controlled hypertension than those who knew at least two complications and two times more likely to have uncontrolled hypertension(AOR 2.140, 95\% CI=1.272-3.600, $p=0.004$ ). Nonadherers to smoking abstinence were four times more likely to have uncontrolled BP than adherent patients $(\mathrm{AOR}=3.935,95 \% \mathrm{CI}=1.065-14.535, p=0.040)$. On the other hand, nonadherers to alcohol abstinence were found to have almost two times risk of developing uncontrolled BP than adherent patients (AOR=2.477, 95\% CI=1.074-5.711, $p=033$ ). Similarly, Khat chewers were nearly two times more likely to have uncontrolled hypertension than nonchewers $(\mathrm{AOR}=2.518,95 \% \mathrm{CI}=1.250-5.073, p=0.010)$ (Table 5).

\section{Discussion}

This study can suggest uncontrolled hypertension as a devastating public health problem. More than half of the patients having treatment had poorly controlled BP, and very little has been studied and done to change this by governmental and public health agencies in the country. Future generation could be salvaged from the growing threat of overwhelming hypertension.

In this study, the prevalence of uncontrolled hypertension is $52.7 \%$, which is almost consistent with studies done at Gondar University Hospital, in northwest Ethiopia, Lebanon, USA, and reported as $53.4 \%, 51.1 \%$, and $54 \%,{ }^{8,10,26}$ respectively. However, it is lower compared to study done in Singapore, and two different health institutions in Nigeria, which was reported as $62.3 \%, 62.3 \%$, and $75.8 \%$, respectively, ${ }^{27,28}$ and this difference might be due to difference in study population (community vs hospital-based study) in Singapore and the difference of urbanization, which is more in Nigeria than Ethiopia and mainly because of discrepancies in environmental factors and lifestyle behaviors such as feeding habits and sedentary lifestyles that bring hypertension to be difficult to control.

Study conducted in central Kenya among hypertensive patients indicated that the level of poor BP is as high as $66.4 \%$ compared to this finding, and this could be because single BP measurements were taken in Kenya in contrast to this study and this may overestimate the prevalence, ${ }^{29}$ and the second possible justification for low uncontrolled hypertension might be that this study used the most conservative method of leveling BP control as uncontrolled using $\mathrm{BP} \geq 140 / 90$ and $\mathrm{BP} \geq 130 / 80$ for general hypertensive patients and with comorbid cases of CKD and DM, respectively, which is in line with the recommendations of JNC7.2

Compared to another study in Ethiopia, the current study is almost lower than Tikur Anbessa Hospital, the capital city of Ethiopia, which was reported as $59.9 \%$. The variation could be because of that the average of 1-year BP measurements was taken in Tikur Anbessa hospital as compared to an average of three consecutive follow-up BP measurements in this study. ${ }^{9}$ 
Table 5 Bivariate and multivariate analysis of factors among adult hypertensive patients at Jimma University Specialized and Teaching, Jimma, southwest Ethiopia, 2016

\begin{tabular}{|c|c|c|c|c|c|}
\hline \multirow[t]{2}{*}{ Variables } & \multicolumn{2}{|c|}{ Blood pressure status } & \multirow{2}{*}{$\begin{array}{l}\text { Crude odds ratio } \\
(95 \% \mathrm{Cl})\end{array}$} & \multirow{2}{*}{$\begin{array}{l}\text { Adjusted odds } \\
\text { ratio }(95 \% \mathrm{Cl})\end{array}$} & \multirow[t]{2}{*}{$p$-Value } \\
\hline & $\begin{array}{l}\text { Uncontrolled } \\
\text { n (\%) }\end{array}$ & $\begin{array}{l}\text { Controlled } \\
\text { n (\%) }\end{array}$ & & & \\
\hline \multicolumn{6}{|l|}{ Age (years) } \\
\hline $18-34$ & $3(15.0)$ & $17(85.0)$ & Reference & Reference & \\
\hline $35-49$ & $37(48.1)$ & $40(51.9)$ & $5.24(1.42-19.35)$ & $7.89(1.86-33.49)$ & 0.005 \\
\hline$\geq 50$ & $134(57.5)$ & $99(42.5)$ & $7.67(2.19-26.89)$ & $9.94(2.52-39.19)$ & 0.001 \\
\hline \multicolumn{6}{|l|}{ Educational status } \\
\hline No formal education & $7 I(5 I . I)$ & $68(48.9)$ & $1.33(0.69-2.55)$ & & \\
\hline Primary education ( $1-8$ grade) & $58(58.0)$ & $42(42.0)$ & $1.76(0.89-3.49)$ & & \\
\hline Secondary education (9-12 grade) & $23(56.1)$ & $18(43.9)$ & $\mathrm{I} .63(0.7 \mathrm{I}-3.74)$ & & \\
\hline College and above & $22(44.0)$ & $28(56.0)$ & Reference & & \\
\hline \multicolumn{6}{|l|}{ Body mass index } \\
\hline Normal & I0I (47.2) & $113(52.8)$ & Reference & Reference & \\
\hline Overweight & $65(67.7)$ & $31(32.3)$ & $2.35(1.42-3.89)$ & $2.24(1.24-4.053)$ & 0.008 \\
\hline Obesity & $8(40.0 \%)$ & $12(60.0 \%)$ & $0.75(0.29-1.89)$ & & \\
\hline \multicolumn{6}{|l|}{ Knowledge on self-care behavior } \\
\hline Knowledgeable & $104(47.5)$ & $115(52.5)$ & Reference & & \\
\hline Not knowledgeable & $70(63.1)$ & $41(36.9)$ & $1.89(1.18-3.01)$ & & \\
\hline \multicolumn{6}{|l|}{ Awareness of HTN complications } \\
\hline Had awareness & $60(42.0)$ & $83(58.0)$ & Reference & Reference & \\
\hline Had no awareness & $114(6 I .0)$ & $73(39.0)$ & $2.16(1.39-3.37)$ & $2.14(1.27-3.60)$ & 0.004 \\
\hline \multicolumn{6}{|l|}{ Medication adherence } \\
\hline Adherent & $94(48.0)$ & $102(52.0)$ & Reference & & \\
\hline Nonadherent & $80(59.7)$ & $54(40.3)$ & $\mathrm{I} .6 \mathrm{I}(\mathrm{I} .03-2.5 \mathrm{I})$ & & \\
\hline \multicolumn{6}{|l|}{ Low-salt diet adherence } \\
\hline Adherent & $46(43.4)$ & $60(56.6)$ & Reference & & \\
\hline Nonadherent & $128(57.1)$ & $96(42.9)$ & $1.74(1.09-2.77)$ & & \\
\hline \multicolumn{6}{|l|}{ Physical activity adherence } \\
\hline Adherent & $84(48.3)$ & $90(51.7)$ & Reference & & \\
\hline Nonadherent & $90(57.7)$ & $66(42.3)$ & $0.68(0.44-1.06)$ & & \\
\hline \multicolumn{6}{|l|}{ Nonsmoking adherence } \\
\hline Adherent & $160(5 \mathrm{I} .1)$ & $153(48.9)$ & Reference & Reference & \\
\hline Nonadherent & $14(82.4)$ & $3(17.6)$ & $4.46(1.26-15.84)$ & $3.94(1.07-14.54)$ & 0.040 \\
\hline \multicolumn{6}{|l|}{ Alcohol abstinence adherence } \\
\hline Adherent & $139(48.8)$ & $\mid 46(5 \mid .2)$ & Reference & Reference & \\
\hline Non-adherent & $35(77.8)$ & $10(22.2)$ & $3.68(I .75-7.7 I)$ & $2.48(I .07-5.7 I)$ & 0.033 \\
\hline \multicolumn{6}{|c|}{ Khat chewing abstinence adherence } \\
\hline Yes & $135(49.1)$ & $140(50.9)$ & Reference & Reference & \\
\hline No & $39(70.9)$ & $16(29.1)$ & $3.68(I .75-7.7 I)$ & $2.52(1.25-5.07)$ & 0.010 \\
\hline \multicolumn{6}{|l|}{ Comorbidity } \\
\hline HTN only & $113(49.6)$ & $115(50.4)$ & Reference & & \\
\hline HTN+chronic kidney disease & $21(72.4)$ & $8(27.6)$ & $2.67(1.14-6.28)$ & & 0.040 \\
\hline HTN+diabetes mellitus & $34(54.0)$ & $29(46.0)$ & $1.19(0.68-2.09)$ & & \\
\hline HTN+others ${ }^{\mathrm{a}}$ & $6(60.0)$ & $4(40.0)$ & $1.53(0.42-5.55)$ & & \\
\hline \multicolumn{6}{|l|}{ No of AHT } \\
\hline Single therapy & 14 (46.7) & $16(53.3)$ & Reference & & \\
\hline Dual therapy & 75 (48.7) & $79(51.3)$ & $1.34(0.58-3.09)$ & & \\
\hline$\geq$ Triple therapy & $85(58.2)$ & $61(41.8)$ & $1.98(0.86-2.57)$ & & 0.025 \\
\hline
\end{tabular}

Note: ancludes congestive heart failure and ischemic heart failure.

Abbreviations: AHT, antihypertensive therapy; $\mathrm{Cl}$, confidence interval; $\mathrm{HTN}$, hypertension.

The majority of the findings of this study are consistent with the findings of other similar works in different countries but some variables have not yet shown a significant association.

While dealing with socioeconomic factors associated with uncontrolled hypertension, the BP control became difficult among those who were at an age range of 35-49 and $\geq 50$ as compared to $18-34$-aged patients ([AOR $=7.893$, 95\% $\mathrm{CI}=1.860-33.493, p=0.005]$, and $[\mathrm{AOR}=9.944,95 \%$ $\mathrm{CI}=2.523-39.188, p=0.001])$, respectively. This specific finding agrees with similar studies in Kenya, JNC7 report, 
Uganda, Lebanon, USA, SSA, and Angola. ${ }^{2,6,10,30,31}$ This finding supports the conclusion that as age increases, the BP is difficult to control because of loss of elasticity of vasculature, which in turn leads to peripheral vascular resistance and raise in $\mathrm{BP}^{32}$

Similarly, this study also revealed that BP control is poor in overweight patients $(\mathrm{AOR}=2.241,95 \% \mathrm{CI}=1.239-4.053$, $p=0.008$ ), as due to weight gain there is increased afterload on the heart or increase in peripheral vascular resistance, which increases cholesterol and triglyceride levels, and decreases HDL levels in the blood, and thereby exacerbate poor BP control $^{33}$ and coherent with similar studies in Uganda, Angola, Singapore, and SSA but BMI had no association in Nigerian studies. ${ }^{27,28,30,31}$

The respondents' awareness of hypertension-related complication revealed that participants who did not know at least two complications were more likely to have uncontrolled hypertension than those who knew at least two complications $(\mathrm{AOR}=2.140,95 \% \mathrm{CI}=1.272-3.600, p=0.004)$ and this idea was also speculated in Algeria. ${ }^{34}$ This might be because having awareness of short- and long-term complications of hypertension leads to fear, frequent visit of health setup, increased health-seeking behavior, and better BP control.

Nonadherence to smoking abstinence has shown significant association with uncontrolled BP (AOR $=3.935,95 \%$ $\mathrm{CI}=1.065-14.535, p=0.040$ ), and this finding is supported by studies in Spain and Singapore. ${ }^{13,27}$ The possible justification has been previously described in detail as smoking leads to enhancement of sympathetic activity, which increases cardiac muscle oxygen demand through escalation of BP, heart rate, and contraction of myocardium. ${ }^{35}$ Moreover, prolonged smoking and even after quoting, it makes arteries to be rigid and tough, which leads to sustained high BP. ${ }^{36}$

While dealing with adherence status to alcohol abstinence, the result revealed that $\mathrm{BP}$ control among nonadherers was low compared to adherers (AOR=2.477, 95\% CI=1.074$5.711, p=033$ ) and it is in line with a study in Uganda ${ }^{30}$ and clinical study, which suggested several mechanisms such as an imbalance of the central nervous system, impairment of the baroreceptors, overstimulation of sympathetic activity, stimulation of the renin-angiotensin-aldosterone system, elevated cortisol levels, increased vascular reactivity due to increase in intracellular calcium levels, stimulation of the endothelium to release vasoconstrictors, and thereby contribute to rise in $\mathrm{BP} \cdot{ }^{37} \mathrm{In}$ this study, Khat chewers were more likely to have uncontrolled hypertension than nonchewers ( $\mathrm{AOR}=2.518,95 \% \mathrm{CI}=1.250-5.073, p=0.010$ ). This finding was supported by studies done among adults in Butajira, Ethiopia. Khat chewing is associated with raised mean
DBP, as the result of cathinone peripheral vasoconstrictor effect. ${ }^{38-40}$ The strength of this study is that the data were collected both from patients' card and patients themselves, which helped the finding to have complete information. Moreover, the H-SCALE survey instrument was highly reliable and demonstrated preliminary validity with previous studies.

\section{Limitations}

There might be social desirability bias, especially on selfreported sensitive issues like cigarette smoking status, chat chewing status, and alcohol intake status, which might result in an overestimate of the number of participants who were abstainers, which can be considered as a study limitation. The level of BP control was determined by analyzing the concurrent comorbid conditions in line with the JNC7 guideline recommendations, and as it has been changed to currently JNC8 guideline, it is considered as a limitation of the study. In addition, adherence to self-care activities and medications was measured by H-SCALE through self-reported interview, and this may cause recall bias and result in eliciting only socially acceptable responses and, hence, may overestimate medication adherence.

\section{Conclusion}

The prevalence of uncontrolled hypertension was high, and more than half of the adult hypertensive patients had poor BP control at Jimma University specialized hospital. The reasons for the suboptimal BP control were poor knowledge of hypertension-related complications, nonadherence to smoking abstinence, nonadherence to alcohol abstinence, Khat chewing, overweight, and middle and older age. Continuous health education on lifestyle practices and hypertensionrelated complications in each follow-up visit through nurses, physicians, and pharmacists are very essential to avert the problem.

\section{Acknowledgments}

The authors thank the participants of the study and Jimma University specialized hospital staffs for their cooperation.

\section{Disclosure}

The authors report no conflicts of interest in this work.

\section{References}

1. Mancia G, Fagard R, Narkiewicz K, et al; ESH/ESC guidelines for the management of arterial hypertension. The task force for the management of arterial hypertension of the European Society of Hypertension (ESH) and of the European Society of Cardiology (ESC). Blood Press 2013;22(4):193-278. 
2. Chobanian AV, Bakris GL, Black HR, et al. Seventh report of the joint national committee on prevention, detection, evaluation, and treatment of high blood pressure. Hypertension. 2003;42(6):1206-1252.

3. Van de Vijver S, Akinyi H, Oti S, et al. Status report on hypertension in Africa-consultative review for the 6th session of the African Union Conference of Ministers of Health on NCD's. Pan Afr Med J. 2013; 16:38.

4. Opie LH, Seedat YK. Hypertension in sub-Saharan African populations. Circulation. 2005;112(23):3562-3568.

5. Iyer AS, Ahmed MI, Filippatos GS, Ekundayo OJ, Aban IB, Love TE, et al. Uncontrolled hypertension and increased risk for incident heart failure in older adults with hypertension: findings from a propensity-matched prospective population study. J Am Soc Hypertens. 2010;4(1):22-31.

6. Centers for Disease Control and Prevention. Vital signs: awareness and treatment of uncontrolled hypertension among adults-United States, 2003-2010. MMWR Morb Morta Wkly Rep. 2012;61:703-709.

7. Hendriks ME, Wit FW, Roos MT, et al. Hypertension in sub-Saharan Africa: cross-sectional surveys in four rural and urban communities. PLoS One. 2012;7(3):1-10.

8. Ambaw AD, Alemie GA, W/Yohannes SM, Mengesha ZB. Adherence to antihypertensive treatment and associated factors among patients on follow up at University of Gondar Hospital, Northwest Ethiopia. BMC Public Health. 2012;12(1):282.

9. Tesfaye A. Blood pressure control associates and antihypertensive pharmacotherapy patterns in Tikur Anbessa General Specialized Hospital Chronic Care Department, Addis Ababa, Ethiopia. Am J Biomed Life Sci. 2015;3(3):41-48.

10. Iyer AS, Ahmed MI, Filippatos GS, et al. Uncontrolled hypertension and increased risk for incident heart failure in older adults with hypertension. J Am Soc Hypertens. 2010;4(1):22-31.

11. Acelajado MC, Calhoun DA. Resistant hypertension, secondary hypertension, and hypertensive crises: diagnostic evaluation and treatment. Cardiol Clin. 2010;28(4):639-654.

12. Buonacera A, Boukhris M, Tomasello SD, et al. Impact of left ventricular remodeling and renal function on $24 \mathrm{~h}-\mathrm{ECG}$ recordings and cardiovascular outcome in elderly hypertensive patients. Eur J Intern Med. 2016;53(5):565.

13. Cordero A, Bertomeu-Martínez V, Mazón P, et al. Factores asociados a la falta de control de la hipertensión arterial en pacientes con y sin enfermedad cardiovascular [Factors associated with uncontrolled hypertension in patients with and without cardiovascular disease]. Rev Esp Cardiol. 2011;64(7):587-593. Spanish.

14. Degli Esposti E, Di Martino M, Sturani A, et al. Risk factors for uncontrolled hypertension in Italy. J Human Hypertens. 2004;18(3):207-213.

15. Wang TJ, Vasan RS. Epidemiology of uncontrolled hypertension in the United States. Circulation. 2005;112(11):1651-1662.

16. Khatib R, Schwalm JD, Yusuf S, et al. Patient and healthcare provider barriers to hypertension awareness, treatment and follow up: a systematic review and meta-analysis of qualitative and quantitative studies. PloS one. 2014;9(1):e84238.

17. Frieden TR, King SMC, Wright JS. Protocol-based treatment of hypertension: a critical step on the pathway to progress. JAMA. 2014; 311(1):21-22.

18. $\mathrm{Hu} \mathrm{H}, \mathrm{Li} \mathrm{G}, \mathrm{Arao}$ T. Prevalence rates of self-care behaviors and related factors in a rural hypertension population: a questionnaire survey. Int J Hypertens. 2013;20(13):1-8.

19. Gohar F, Greenfield SM, Beevers DG, Lip GY, Jolly K. Self-care and adherence to medication: a survey in the hypertension outpatient clinic. BMC complement Altern Med. 2008;8:4.

20. Ragot S, Sosner P, Bouche G, Guillemain J, Herpin D. Appraisal of the knowledge of hypertensive patients and assessment of the role of the pharmacists in the management of hypertension: results of a regional survey. J Hum Hypertens. 2005;19(7):577-584.
21. Macro OR, Measure DH. Ethiopia Demographic and Health Survey: Preliminary Report. Central Statistical Agency; 2011. Available from: https://www.google.co.nz/url? sa $=\mathrm{t} \& \mathrm{rct}=\mathrm{j} \& \mathrm{q}=\& \mathrm{esrc}=\mathrm{s} \&$ source $=\mathrm{we}$ $\mathrm{b} \& \mathrm{~cd}=2 \& \mathrm{cad}=$ rja $\&$ uact $=8 \& \mathrm{ved}=0 \mathrm{ahUKEwj} 5 \mathrm{k} \_\mathrm{rm} 8 \mathrm{ePSAhWGm} 5$ QKHZUOBHUQFggiMAE\&url=https\%3A\%2F\%2Fdhsprogram. com\%2Fpubs $\% 2$ Fpdf $\% 2 F P R 10 \% 2$ FPR 10 .pdf\&usg=AFQjCNH4T1M GS4Uu1VhbEDfLr6t0NE5rhQ\&sig2=5OIC2oXcfXqSD2GTaiCMpw \&bvm=bv.150120842,d.dGo. Accessed March 20, 2017.

22. Anthony D, Heyman MB, Gross R, Tabenkin H, Porter B, Porath A. Factors associated with hypertensive patients' compliance with recommended lifestyle behaviors. Isr Med Assoc J. 2011;13(1):533-557.

23. Yi-Bing Wang D-GK, Long-Le Ma, Le-Xin Wang. Patient related factors for optimal blood pressure control in patients with hypertension. Afr Health Sci. 2013;13(3):579-583.

24. Janssen I, Katzmarzyk PT, Ross R. Body mass index, waist circumference, and health risk: evidence in support of current national institutes of health guidelines. Arch Intern Med. 2002;162(18):2074-2079.

25. Warren-Findlow J, Seymour RB. Prevalence rates of hypertension self-care activities among African Americans. J Natl Med Assoc. 2011;103(6):503.

26. Farah R, Zeidan RK, Chahine MN, Asmar R, Chahine R, Salameh P, et al. Predictors of Uncontrolled Blood Pressure in Treated Hypertensive Individuals: First Population-Based Study in Lebanon. J Clin Hypertens. 2016;110(21):340-347.

27. Tan EK, Chung WL, Lew YJ, Chan MY, Wong TY, Koh WP. Characteristics, and Disease Control and Complications of Hypertensive Patients in Primary-care - A Community-based Study in Singapore. Ann Acad Med Singapore. 2009;38(10):850-856.

28. Abiodun OO, Balogun MO, Adebayo RA, Akintomide AO. Blood pressure control and exaggerated blood pressure response in Nigerians with essential hypertension. Clin Med Insights Cardiol. 2014;8:53-56.

29. Mutua EM, Gitonga MM, Mbuthia B, Muiruri N, Cheptum JJ, Maingi T. Level of blood pressure control among hypertensive patients on follow-up in a regional referral hospital in Central Kenya. Pan Afr Med J. 2014;18:278.

30. Musinguzi G, Van Geertruyden JP, Bastiaens H, Nuwaha F. Uncontrolled hypertension in Uganda: a comparative cross-sectional study. J Clin Hypertens. 2015;17(1):63-69.

31. Pires JE, Sebastião YV, Langa AJ, Nery SV. Hypertension in Northern Angola: prevalence, associated factors, awareness, treatment and control. BMC Public Health. 2013;13(1):90.

32. Mutua EM, Gitonga MM, Mbuthia B, Muiruri N, Cheptum JJ, Maingi T. Level of blood pressure control among hypertensive patients on follow-up in a Regional Referral Hospital in Central Kenya. Pan Afr Med J. 2014;18:278.

33. Richard N. Overweight and Obesity-Related Hypertension. Ochsner J. 2009;9(3):133-136.

34. Ghembaza M, Senoussaoui Y, Kendouci Tani M, Meguenni K. Impact of patient knowledge of hypertension complications on adherence to antihypertensive therapy. Curr Hypertens Rev. 2014;10(1):41-48.

35. Najem B HA, Houssiere A, Pathak A, et al. Acute cardiovascular and sympathetic effects of nicotine replacement therapy. Hypertension. 2006;47:1162-1167.

36. Jatoi NA, Jerrard-Dunne P, Feely J, Mahmud A. Impact of smoking and smoking cessation on arterial stiffness and aortic wave reflection in hypertension. Hypertension. 2007;49(5):981-989.

37. Husain K, Ansari RA, Ferder L. Alcohol-induced hypertension. World $J$ Cardiol. 2014; 6(5):245-252.

38. Getahun W, Gedif T, Tesfaye F. Regular Khat (Catha edulis) chewing is associated with elevated diastolic blood pressure among adults in Butajira, Ethiopia: a comparative study. BMC Public Health. 2010;10(1):390.

39. Ayana AM, Sherief HT, Tekli Y. Effect of khat (Catha edulis Forsk) on blood pressure and heart rate, a community based study. Ethiop J Health Dev. 2002;16(3):325-334.

40. Berhane Y, Bonita R, Wall S, Tesfaye F, Byass P. Association of smoking and khat (Catha edulis Forsk) use with high blood pressure among adults in Addis Ababa, Ethiopia. Prev Chronic Dis. 2008;5(3):A89. 
Research Reports in Clinical Cardiology

Research Reports in Clinical Cardiology is an international, peerreviewed, open access journal publishing original research, reports,

Visit http://www.dovepress.com/testimonials.php to read real quotes editorials, reviews and commentaries on all areas of cardiology in the clinic and laboratory. The manuscript management system is completely online and includes a very quick and fair peer-review system.

Submit your manuscript here: https://www.dovepress.com/research-reports-in-clinical-cardiology-journal 